\title{
Porcelain enamel coatings, from the past to the future: solved and unsolved issues for the improvement of their mechanical properties.
}

\author{
Created by: QStefano Rossi , PFrancesca Russo \\ Version received: 1 May 2020
}

check for updates

\begin{abstract}
Porcelain enamel coatings have their origins in ancient times when they were mainly used for decorative and ornamental purposes. From the industrial revolution onwards, these coatings have started to be used also as functional layers, ranging from home applications up to the use in high-technological fields, such as in chemical reactors. The excellent properties of enamel coatings, such as fire resistance, protection of the substrate from corrosion, resistance to atmospheric and chemical degradation, mainly depend and originate from the glassy nature of the enamel matrix itself. On the other side, the vitreous nature of enamel coatings limits their application in many fields, where mechanical stress and heavy abrasion phenomena could lead to nucleation and propagation of cracks inside the material, thus negatively affecting the protective properties of this coating. Many efforts have been made to improve the abrasion resistance of enamelled materials. On this regard, researchers showed encouraging results and proposed many different improvement approaches. Now it is possible to obtain enamels with enhanced resistance to abrasion. Differently, the investigation of the mechanical properties of enamel coatings remains a poorly studied topic. In the literature, there are interesting methodological ideas, which could be successfully applied to the mechanical study of enamelled materials and could allow to have further insights on their behaviour. Thus, the path that should be followed in the future includes the mechanical characterization of these coatings and the search for new solutions to address their brittle behaviour.
\end{abstract}

\section{Introduction}

The art of enamelling has noble and ancient origins. It is mostly impossible to determine exactly when and who started enamelling metallic objects, but it is a common opinion that this art had a great impetus around the $15^{\text {th }}$ century $\mathrm{BC}$ in the Mediterranean area of Mycenae and Cyprus [1]. Enamelling has been used for a long time only for decorative and ornamental use: enamel coatings were applied on precious metal objects to enrich them with polychromatic and shining decorations, as they were precious stones. Until the $16^{\text {th }}$ century, the character of enamelled works was mainly symbolic or religious; after this period, and in particular, in the $16^{\text {th }}$ and $17^{\text {th }}$ centuries, enamelling began to become art and new techniques were developed. With the advent of the industrial revolution, enamel began to arise interest as it could be a low-cost coating for many functional applications[2][3]: thus, technical enamelling was created. At the end of the $18^{\text {th }}$ century enamelling of iron, cast iron and copper alloys were patented, giving impetus to the use of enamelled objects in the everyday life of thousands of families. In the early decades of the $20^{\text {th }}$ century, enamel was massively present in people's homes in the form of stoves, hobs, clocks, bathtubs, and sinks[4][5]6]. The use of enamelled metals was drastically reduced by the advent of polymers in the 1960s but only 20 years later a new era of modern enamelling started. From that moment up to now, the use of enamelled metals has been mostly exploited for high-duty technological applications, leaving behind the "pop" applications of the first half of $20^{\text {th }}$ century.

Porcelain enamel coatings are mainly constituted by silica, combined with many different acid, basic and amphoteric oxides. The starting step of enamel-making is the production of the frit $[7]$. The frit is a glass that is produced at temperatures about $1400 \square \mathrm{C}$ and then rapidly quenched to obtain small glass granules. The average chemical composition of a ready-to-use frit is the following: $\mathrm{SiO}_{2}<40$ wt. $\%, \mathrm{Na}_{2} \mathrm{O}+\mathrm{Li}_{2} \mathrm{O}+\mathrm{K}_{2} \mathrm{O}<35 \mathrm{wt} . \%, \mathrm{~Tb}_{2} \mathrm{O}+\mathrm{Al}_{2} \mathrm{O}_{3}<20$ wt.\%, $\mathrm{B}_{2} \mathrm{O}_{3}<5$ wt.\%, $\mathrm{SrO}+\mathrm{SbO}_{3}+\mathrm{ZnO}_{2}+\mathrm{P}_{2} \mathrm{O}_{5}<5$ wt. \%[1][2][5][8][9][10][11]. The formulation of the frit is a key aspect to be taken under consideration, as it determines the main physical and chemical features of the enamel and it assures the formation of a flawless covering surface on the metal objects. The frit, after proper grinding, can be applied on different substrates using wet or dry techniques[1][3][7]. Enamelling by wet techniques requires the frit to be mixed with a dispersing medium (water), clays and additives to produce an easily applicable slip; then the slip can be applied by dipping, spraying (electrostatic or not) or flow coating, dependent on the required properties or object 
shape. The dry powder electrostatic technique, where the frit is electrically charged and applied to the object, is mainly used to obtain homogeneous and thick covering on even geometrically complex objects ${ }^{[7]}$. In the last decades, besides the well-established application techniques, electrophoresis is increasing more and more interest as an effective deposition technique. After dry or wet application, the enamel is dried up by a mild heat treatment, in order to make the residual water evaporate. After this step, the specimen is fired at an appropriate temperature to obtain the vitrification of the coating layer and an irreversible enamel-metal adhesion[3][7]. Enamel coatings can be now applied to a wide range of substrates, ranging from steel and cast iron to aluminium alloys and metallic foams[12][13][14]. Nowadays, enamel coatings are mainly used in high-duty technological applications, where the effective protection of metallic substrates plays an important role. Enamel coatings show very interesting technological properties, such as corrosion protection, resistance to heat and flame, chemicals and weathering, and they maintain their aesthetical properties (gloss and colour) unchanged in time.

\section{The properties of enamelled materials and their application}

Many studies and books report and describe the properties of enamelled materials listing the main technological properties they entail and showing some examples. Here, today, we will go through this topic, but following an opposite approach.

Probably, the most common and well-known application of enamel coatings iskitchenware. The reason is obvious, as enamel is characterized by good resistance to heat, thermal shock and direct flame[2][7][13]. It should be noticed that the enamel layer is often not only applied on the outer part of the pans, which is in contact with the stove, but also on the inside, in contact with food. Enamel coatings have low-wettability, thus resulting in non-stick and easy-cleanable surfaces, suitable for application in the kitchenware field. In addition to that, the chemical inertia of the glassy matrix makes enamelled kitchenware resistant to detergents and to the absorption of smells and flavours. Enamel lives in hour homes hidden inside a common household appliance: the oven. The application of enamel on the inner walls of the oven allows to provide an easy-to-clean surface, which shows resistance to aggressive chemicals and abrasion; in addition to that, special catalytic or pyrolytic enamels allow to keep the oven surfaces clean, destructing food greases and remains ${ }^{[15]}$. Another functional application of enamel inside our houses is represented byfireplaces and chimney pipes. Fireplaces represent a harsh environment for any material, as high temperatures, charcoal and ash can affect the coating durability, with the production of acid condensate, but enamels represent a suitable candidate to withstand these conditions and provide unique aesthetic characteristics at the same time. As well as stoves, chimney pipes need to be resistant to corrosion, smoke, gases and abrasion due to small particles dispersed in the gases; enamel coatings can be successfully used also for this special application. Nowadays, enamel coatings are used in a huge variety of design and functional objects, such as radiant panels, design basins and furniture objects, mainly because they can be produced in an infinite palette of colours with different surface finishing and they maintain their aesthetical properties unchanged in time, differently respect to what happens to (organic) paints ${ }^{[16][17]}$. We probably never noticed, leaving our homes, that enamel can be found almost everywhere. The application of enamelled materials in the infrastructure filed is commonly widespread. Let us consider, for example, the usage of enamelled steel panels in highway tunnels. In this case, enamel coatings can provide uniform illumination while resisting the attacks of combustion by-products, dust, and chlorides due to road salt, also withstanding high humidity and harsh abrasion. Another application of enamelled panels can be found in airports, train stations and subways: this material allows the surfaces to be easily cleaned and disinfected, making these environments look like modern and technological at the same time. Enamelled materials can retain colour and gloss also when exposed to aggressive environments and are able to withstand UV light degradation and corrosion[3][5]. These reasons make enamel coatings very useful in thebuilding field, where are used like covering panels, and in the safety and tourism signposting field, especially thanks to their ability to resist organic solvents and be anti-graffiti. One of the most know industrial application of enamel coatings is the protection of chemical reactors. Is very common for chemical reactors to be covered by enamel coatings both in the outer and inner part. Enamel coatings can be applied both to prevent the corrosion of the metallic substrate but also to prevent the contamination of the content of the reactor, as usually happens in equipment used by pharmaceutical industries.

Enamelled materials are commonly used in the infrastructure, automotive, building and industrial field for the unique 
properties they entail, but all this glory has a scientific reason to exist. Figure 1 illustrates some example in which enamel coatings find application.

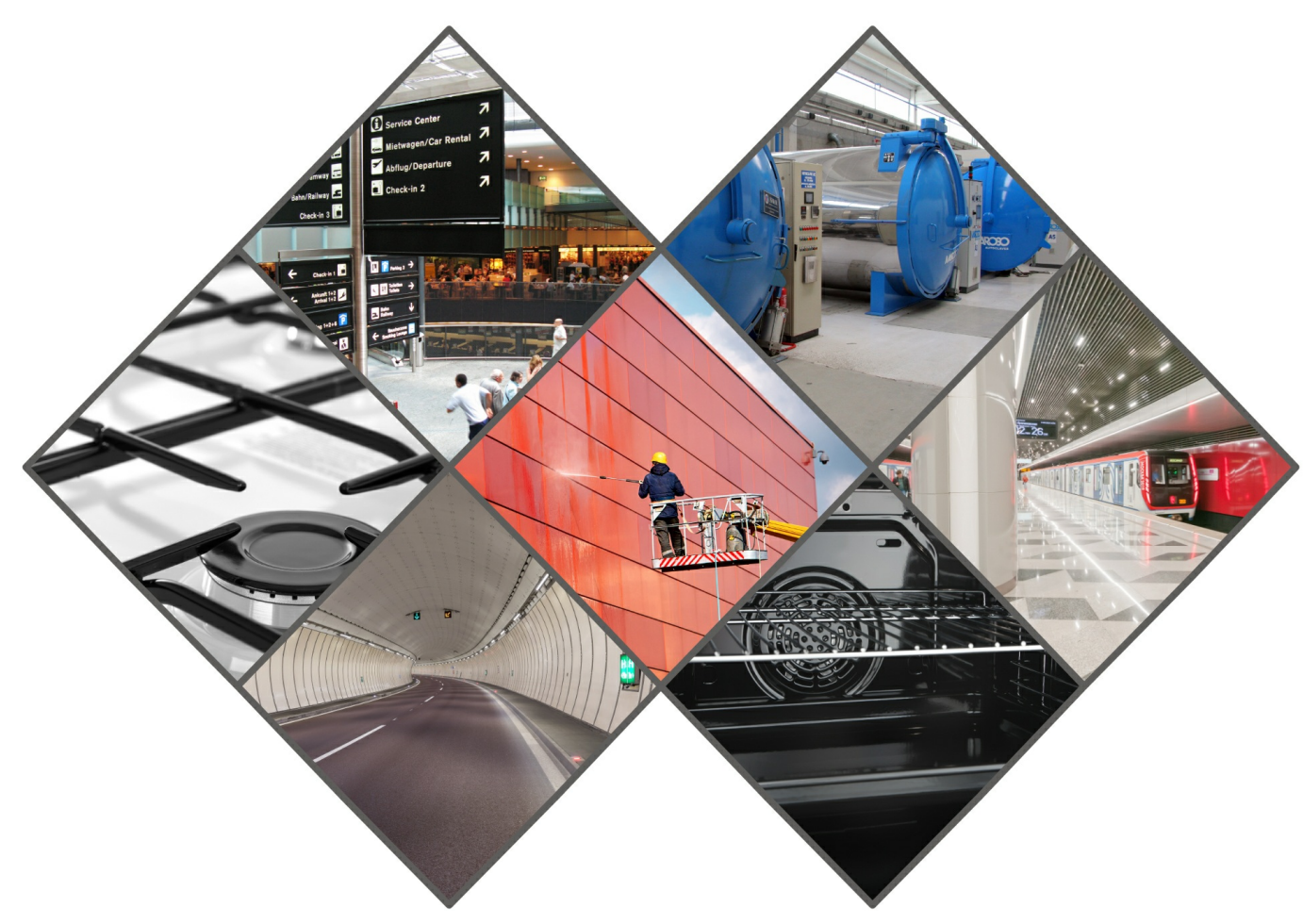

Figure 1: Illustration of some common application fields for enamel coatings.

The reason why enamelled materials show all the described properties is inherent in the structure of enamel coatings itself. If it could be possible to easily cut an enamelled steel panel, we would see two completely different materials tightly coupled together. The strong bond between the glassy coating and the metallic substrate manifests itself in the strong adherence between the two materials, avoiding the detachment of the coating from the steel substrate $[17][18][19][20]$. But, how could glass and metal form such an unbreakable bond? During the firing step, previously described, many chemical-physical reactions occur between the two materials: as the temperature increases the metal substrate oxidizes as the oxygen still diffuses from the outer atmosphere through the enamel layer; as the firing temperature is reached the enamel layer turns into a viscous liquid, wetting all the substrate surface and dissolving the iron oxides, present on the metal surface ${ }^{[3][7]}$. Many chemical reactions occur between the iron oxides and the adherence oxides present in the enamel formulation, thus forming a dendritic structure on the metal, where the liquid enamel can penetrate and mechanically hang. This is the origin of the strong adhesion existing between the coating and the metallic substrate. The enamel layer structure is constituted by a homogeneous compact layer; however, in the microstructure, it is possible to notice the presence of porosity and bubbles [2][3][7]. The porosity is a typical feature of this kind of material, as it is due to the evolution of gases during the firing process[2][3][5]. The number and size of the pores can be adjusted changing the composition of the frit, the process parameters, the rheology of the slip and also adding different kinds of both organic and inorganic additives. The strong adhesion between the coating and the substrate is the main reason why enamel coatings show optimal corrosion protection properties and can withstand a certain amount of bending without detachment or flake production[21][22][23]. The glassy 
nature of the matrix makes this coating inert and resistant to chemicals and weathering, but it is also a factor that limits the application of this kind of material in many fields. Enamels show non-excellent abrasion and mechanical resistance, despite their high surface hardness, mainly because they behave like a brittle material[24][25]. Then, abrasion and mechanical solicitation could cause a loss of functional properties and cracks may develop and propagate in the coating until reaching the substrate ${ }^{[24]}$.

For these reasons, the improvement of enamel coatings mechanical properties represents a priority to be addressed as soon as possible. Many attempts have been made in recent years to improve the abrasion resistance of these coatings and interesting solutions have been shown out. On the other side, the scientific community is still searching an effective way to improve the resistance of these coatings to bending and tensile stress, as well as is focusing attention on the improvement of enamel coatings fracture toughness.

\section{Abrasion resistance of enamel coatings}

Abrasion resistance is certainly a characteristic that distinguishes enamelled materials form organic coatings, such as paints. Resistance to wear and mechanical damage caused by external agents is a key feature for a surface that is exposed to aggressive environments during its service life, like happens to enamel coatings.

As already described, enamel coatings are vitreous layers with an enough high surface hardness, that make them particularly resistant to surface and sub-surface abrasion. On the other side, the nucleation and propagation of cracks and the disclosure of the enamel intrinsic porosity, occurring during abrasion phenomena, could negatively affect the protection properties this coating guarantee to the metal substrates. In the case of surface abrasion, the damage mechanism is limited to the first layers of the coating, causing an increase of roughness, a decrease of gloss and sometimes also colour changes[ㅌ]. In the case of sub-surface abrasion, the damage mechanism includes a loss in weight and removal of material, also affecting the functionality of the coating itself[27][28][29]. Thus, abrasion damages should be limited to preserve both the aesthetical and the functional properties of enamel coatings. There are three possible ways to address this issue: the modification of frit composition, the addition of mill additives and the addition of hard particles to the enamel matrix. It is important to point out that the addition of mill additives or hard particles represent a cost for industries, then it is necessary to find solutions that do not have detrimental effects on other coating properties.

Many studies regarding the improvement of abrasion resistance by the addition of mill additives are published in the literature [27][30][31]. A quite common approach consists in the addition of quartz in concentrations up to 10 wt.\%. The addition of quartz in high concentrations, given the fact that it is the main component of the frit itself, reduce the concentration of melting oxides and quartz particles are not completely solubilized. Other studies pointed out the positive effect of the addition of potassium feldspar in concentrations up to $10 \mathrm{wt} . \%$ [27]. Both quartz and feldspar have a good compatibility with the enamel matrix, and they can improve the abrasion resistance, without leading to loss of aesthetical properties. On the other side, the addition of spodumene $\left(\mathrm{LiAl}\left[\mathrm{Si}_{2} \mathrm{O}_{6}\right]\right)$ or zirconium silicate $\left(\mathrm{ZrSiO}_{4}\right)$ could rise negative effects, as their solubility in the coating is very limited[32][30].

Another possible way to improve the abrasion resistance of these coatings is represented by the addition of hard particles. Many studies about the effects of hard particles such as $\mathrm{SiC}$, WC and $\mathrm{Al}_{2} \mathrm{O}_{3} \quad \mathrm{were}$ recently published[26][30][31]. All the three different particles have positive aspects regarding the improvement of abrasion resistance, but some factors, as the particle dimension, concentration, and agglomeration, may be considered.

Another, probably more innovative way, to improve enamel abrasion resistance could be represented by the addition of particles with self-lubricant properties, such as graphite[30]. In the past, the addition of graphite particles was showed not to be so effective, as agglomeration phenomena take place and enhance the degradation of the coating by chipping of big portions of enamel. New advancements have been reached in the last two years in this regard, allowing a uniform dispersion of graphite into the enamel matrix ${ }^{[33]}$ and opening a new way in the study of abrasion resistance of these kinds of coatings. 


\section{Bending behaviour of enamel coatings and their fracture toughness}

Given that the brittle behaviour is one of the characteristics that limit the application of enamel coatings in many fields, it seems of interest to thoroughly study the mechanical behaviour of these coatings. The literature is rich in studies conducted regarding the abrasion resistance of enamelled coatings, but at the same time, it offers limited and fragmented information on the mechanical performances of these coatings. It is then necessary to experimentally determine the stiffness and fracture behaviour of these vitreous coatings and find solutions able to improve their mechanical properties.

The first attempts made to estimate the flexural behaviour of enamelled materials date to the late 20 century. A. Andrew and K. Shaw [3][34] published some graphical tables, which allow to estimate the mechanical behaviour of the enamelled material, knowing the geometric parameters of the specimen and the elastic properties of both the coating and the substrate. These tables could be a useful tool for the estimation of the bending behaviour of enamelled materials, but their main limit is represented by the assumption to deal with symmetrical samples. Over the years, the fast development of thin ceramic coatings has put attention on the requirement for new experimental approaches to characterize the mechanical properties of these materials and measure their elastic modulus and strength. Among all the possibilities, indentation is the more popular characterization method, but it shows some intrinsic limits, as it only measures local properties. Since hard ceramic coatings are tightly bonded to the substrates and can be hardly separated from these substrates, it is not possible to characterize their properties exploiting methods which are commonly used for monolithic specimens. Considering these limits, it is important to take advantage of traditional flexural tests, such as 4-points and 3-points bending tests, trying to get some useful information.

Rossi et al. ${ }^{[13]}$ showed that it is possible to obtain and quantify the bending modulus of elasticity of the composite enamel-substrate system and evaluate the enamel coating brittleness as well. Their study was focused on the mechanical characterization of enamelled aluminium foams. The chosen approach consisted in the recording of forcedisplacement curves during 4-points bending tests and in the consequent quantification of the bending stiffness of the substrate-enamel system. The results were shown as relative bending stiffness respect to the uncoated substrate. This experimental approach was found to deliver interesting results as the mechanical properties of enamel and aluminium foams are very different, but it should be noted that its application could experience important limits when dealing with aluminium alloys or steel enamelled samples. Rossi et al. ${ }^{[3]}$ also evaluated the coating brittleness individuating the "First Crack Failure" (FCF) point in the load-displacement curves and calculating the FCF parameter value. The FCF parameter is an adimensional number used to describe the cracking behaviour of the coatings, and it can be easily calculated knowing the first crack onset displacement and the thickness of the sample. The ease with this parameter can be calculated does not reflect the ease with the first crack onset displacement can be individuated, as in many cases it is not possible to identify a sudden decrease of the load-displacement curve.

Considering these limits, Bao et al! $\stackrel{[35]}{6}$ demonstrated that is possible to exploit traditional 4-points bending tests and characterize the mechanical properties of hard ceramic coatings on metallic substrates following an indirect approach. It is then possible to obtain the elastic modulus of the coating layer knowing the moduli of the bare substrate and the coated system, as it is possible to determine the bending strength of the coating layer using the bending strength of the coated system and the critical load for cracking (i.e. the load corresponding to the FCF). Thus, Bao et al. ${ }^{[35]}$ demonstrated that, when the elastic modulus and bending strength of a coated system are measured directly by traditional tests, the elastic modulus and strength of the coating layer can be determined by simple equations. This approach was successfully exploited by Rossi et al. ${ }^{[14]}$ to characterize enamelled aluminium foams samples. Despite the many advantages this method offers, it is necessary to highlight the boundary conditions necessary for the results to be reliable. No interface slip between the coating and the substrate should occur, and, in the case of very thin coating layers $(\mathrm{h}<0.1 \mathrm{~mm}$ ), the substrate thickness $\mathrm{H}$ should also be relatively small to make the ratio $\mathrm{R}=\mathrm{h} / \mathrm{H}>1 / 30$. In addition to that, it is important to underline that it is very difficult to determine the FCF point for brittle coatings deposited on ductile substrates. In order to overcome this issue, the acoustic emission (AE) technique can be effectively used to determine the FCF point. 


\section{Encyclopedia}

The use of AE to study the cracking modes in coated materials was introduced in the 1980 s and from that moment up to now, it has been used to characterize the mechanical properties of different kind of coatings. The AE technique can be coupled with traditional fracture mechanics measurements to obtain a complete overview on the mechanical behaviour of the selected material, predict failure and monitor damage evolution. $A E$ is a term describing a class of phenomena whereby transient elastic waves are generated by a rapid release of energy from localized sources within a material. Three main types of $\mathrm{AE}$ data analysis can be carried out to characterize the properties of a coating: $\mathrm{AE}$ activity, $A E$ parameter and $A E$ frequency analysis. The first one measures the amount of $A E$ signals produced by a specimen and it gives information about the nucleation and evolution of damage during a mechanical test. The second data analysis type uses AE signal parameters, such as amplitude energy and duration, in order to evaluate the severity of damage and discriminating between different damage types. The latter data analysis type is very complex, but it has found applications in discriminating between different damage mechanisms. Among all the listed AE data analysis methods, the AE activity analysis is widespread as it allows to detect the onset of coating damage measuring the cumulative $A E$ hits and have direct information about the integrity of the sample.

One example of this kind of AE data analysis is reported by M. Miguel et a $[36]$. Their study was focused on the combined characterization of thermal sprayed coating by AE activity technique during 4-points bending tests and SEM observations. This study highlights the possibility to follow the damaging process of a coating recording the cumulative number of hits of $\mathrm{AE}$ waves during a bending test, where a hit is defined as a signal that crosses a defined threshold amplitude. The abrupt change in the cumulative hit number allowed to identify the onset of four different damaging stages, characterized by different cracking mechanisms. In particular, they showed that the damaging process starts with the formation of friction points near the rollers, then the segmentation process starts (formation of cracks perpendicular to the coating surface), until rapid crack propagation is produced in the third stage, when the cracks reach the substrate and cause delamination processes (fourth stage). They noticed that the different cracking mechanisms are also characterized by different maximum hit amplitudes: the maximum hit amplitude is recorded in the third stage when cracks rapidly propagate through the coating. The same experimental approach was also used by U. Wiklund et al. [37]. In this case, the scientists highlighted the good agreement existing between crack density measurements and $\mathrm{AE}$ data analysis, both useful to estimate the cracking resistance of different kind of coatings. In particular, the cracking resistance of a coating can be evaluated finding the threshold from which on a rapid increase in $\mathrm{AE}$ events or cracking density is observed: the higher is this threshold, the higher is the cracking resistance of the coating. A more detailed study regarding the coupling of in-situ AE tests during 4-points bending tests with SEM analysis was carried out by Dalmas et al.[38] on WC-Co coated materials. They were able to study the amplitude, cumulative hit number and absolute energy of the AE signals, linking the occurrence of these events to specific damage mechanisms in the coating. In addition to that, they carried out an analysis of $A E$ waves in order to localize the source of the signals in the coating. The analysis of $\mathrm{AE}$ signals can be either qualitative or quantitative. The latter type usually involves the inverse processing of $A E$ data, a quite complex data analysis to be carried out routinely. Despite the complexity of this data analysis type, important insights on the damage modes and sources can be

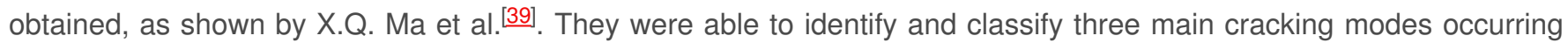
in plasma-sprayed thermal barrier coatings: vertical segmentation, shear delamination and horizontal cracking in the top layer or at the interface with the substrate. One very clear thing, that emerges from these studies, it the great potentiality inherent in using traditional mechanical testing methods combined with the AE analysis. Dal Re et al. $\frac{[40]}{4}$ studied the bending behaviour of enamel coatings combining the traditional 4-points bending test with the parametric AE analysis. They determined the bending modulus of elasticity and the FCF parameter for different types of enamel coatings, putting into relation their mechanical properties with the hardness and microstructure of the coatings themselves. They found out that FCF parameter, as the coating toughness, increases when the enamel coating has a low porosity and the pores are of little dimensions and with a high circularity. On the other side, they found an inverse relationship between the coating toughness and its density and hardness; mainly because the more rigid is the coating, the more it tends to show a brittle behaviour. Thus, it is possible to say that the traditional bending tests, coupled with microscopic observations and $\mathrm{AE}$ analysis could really be helpful to investigate the mechanical properties of thin hard ceramic coatings and forecast the failure mechanism occurring in these materials. However, it is important to specify that many of the mechanical properties extrapolated from flexural tests, can also be obtained exploiting tensile tests. 
The study of enamel coatings mechanical properties is very important, but another important thing to be taken under consideration is the measurement of their fracture toughness and the improvement of their fracture behaviour. Fracture toughness is a property of the material that only takes account of the energy required to facilitate the crack propagation to fracture and it is easily measured for bulk materials. On the other side, the fracture toughness measurements for thin films is very difficult to be exploited, mainly due to the small dimension in thickness and presence of a substrate. The quantitative assessment of the fracture toughness can be done by stress-based or energy-based approaches, as extensively discussed by S. Zhan et al. ${ }^{[41]}$, but no standard procedure exists. Examples of stress-based approaches are for example bending test with pre-cracks, crack length evaluation and scratch test. The first approach takes advantage of a well-established mechanical testing method but the introduction of a pre-crack into the substrate may have significant effects on film deposition and affect the fracture toughness values as well. This is the reason why some researchers ${ }^{[37][2]}$ decided to exploit bending without pre-crack and use the "cracking resistance" as an indirect measure of fracture toughness. The cracking resistance is defined as the threshold strain over which density of cracks sharply increases and can be measured by AE analysis or by directly measuring the crack density as a function of strain. This approach could be very useful to have preliminary information on the fracture behaviour of thin films. The last stress-based approach is represented by the scratch test. This testing method is usually accepted as one of the simpler techniques to assess adhesion strength of coating layers. In this test, a diamond tip is driven over a surface to produce a scratch and the load applied is linearly increased until it is sufficiently high to cause the adhesive failure of the coating. For hard films, microcracks appear also before the final adhesive failure of the coating at the, so defined, lower critical load. It is then possible to evaluate the cracking resistance of different coatings considering the value of the lower critical load, but crack initiation does not necessarily mean failure of the coating. Thus, the more reliable approach to have a qualitative assessment of the film toughness consist in measuring the "Crack Propagation Resistance" (CPR), which is calculated by using both the lower critical load and the higher critical load (i.e. the load at which coating adhesive failure occurs) ${ }^{[43}$. The use of stress-based methods usually does not deliver quantitative direct measurements for film toughness, thus it is necessary to exploit energy-based methods, such as tensile tests. Zhang et al. ${ }^{[4]}$ have proposed a two-steps uniaxial tensile method to characterize hard film toughness. In this method, the film-substrate system is subjected to uniaxial tensile stress until the thin coating layer fractures, while the substrate is still elastic. After the load is removed and the substrate complete elastically recovers, the system is subjected to a second loading until the previous extension. The film toughness is then obtained calculating the strain energy difference before and after cracking and knowing the geometrical parameters of the specimen, the Young modulus of the coating layer and the crack density (obtained by scanning electron microscopy investigations). The advantage of this method lies in its independence from the substrate, as the tests must be carried out in the substrate elastic behaviour regime. Other important requirements are the perfect adhesion that must exist between the coating and the substrate, and the warranty of plain stress condition. Considering the requirements and the calculations required, it is possible to state this method has several advantages respect to other characterization techniques and it can easily deliver a quantitative estimation of the film fracture toughness. It could be then possible to use this method to characterize the fracture toughness of enamel coatings, but some limitations arise in this regard. The method proposed by Zhang et al. ${ }^{[44]}$ requires the graphical individuation of the FCF point, which can be difficult to be detected, as previously explained, when the thickness ratio between coating and substrate is too low. This limitation can be easily solved by using the $A E$ activity analysis. For completeness, it is important to point out that these results obtained using this two-step uniaxial method are comparable to the toughness values obtained by indentation methods. Although the two methods can find good agreement, the indentation technique has major drawbacks as the crack length should be evaluated on radial cracks only and the calculation should consider the effect of the substrate. For this reason, the tensile method seems to be more promising as it allows to estimate the properties of the film avoiding local measurements.

\section{Conclusions}

Enamel layers are types of coatings with excellent functional and aesthetic properties, which ensure high performances in many fields of application. Their excellent characteristics, such as the protection of the substrates from corrosion, the resistance to heat, chemical attacks and abrasion are mostly due to the glassy nature of the matrix of the coating itself and to its internal structure. However, the glassy nature of these coatings also makes them 
susceptible when subjected to intensive abrasive phenomena or mechanical stress. The mechanical action of external agents can cause the onset and the propagation of cracks in the material, with detrimental effects on their protective and functional properties. For this reason, over the years, many studies have been carried out to improve the mechanical properties of these coatings. Many studies have concerned, for example, the improvement of the abrasion resistance of these coatings by adding mill additives or hard particles. Positive results have been obtained in some cases, while, in others, the ineffectiveness of some additives has been demonstrated. Recent studies have focused on the possibility of adding self-lubricant particles to the glass matrix: good results have recently been achieved, which will allow further developments in this field soon. As regards the characterization of the enamel coatings mechanical properties and fracture toughness, very few studies are available in the literature. Despite this, the mechanical investigation of enamelled coatings is vital because, in order to expand the range of applications, it is necessary to be able to measure these properties and find solutions to improve them at the same time. The literature is rich in useful indications on how to proceed to characterize the mechanical properties of thin hard ceramic coatings, and all these approaches could be applied to enamel coatings as well. The more solid and reliable methods are based on the combined use of traditional flexural and tensile testing techniques with the AE analysis and SEM observation. Well, using this knowledge it is then possible to start studying on how to improve these properties, by adding additives, particles or hard fillers and give enamel coatings new market opportunities.

\section{References}

1. A. H. Dietzel, Emaillierung - Wissenschaftliche Grundlagen und Grundsatze der Technologie, Springer Verlag, Berlin/Heidelberg, 1981.

2. A. Petzold, H. Poschmann, Email und Emailliertechnik. second ed., Deutscher Verlag fur Grundstoffindustrie, Leipzig, 1992.

3. A. I. Andrews, Porcelain Enamels: the preparation, application and properties of enamel, second ed., The Garrard Press, Champaign (IL), 1961.

4. B. T. Garland, The designing of products utilizing the special properties of vitreous enamel, Mater. Des. 7 (1986) $44-48$. https://doi.org/10.1016/0261-3069(86)90037-3.

5. A. Umbertazzi, N. Wojciechoswki. Smalto Porcellanato - vitreous enamel, Ulrico Hoepli Editore, Milano, 2002.

6. F. A. Kuchinski, Corrosion resistant thick films by enamelling, in: J. B. Wachtman, R. A. Haber (Eds.), Ceramic films and coatings, Noyes Publication, Park Ridge (NJ), 1993, pp. 77-130.

7. S. Pagliuca, W. D. Faust, Porcelain (vitreous) enamels and industrial enamelling processes - the preparation, application and properties of enamels, The International Enamellers Institute, Mantova, 2011.

8. T. Zhaolin, F. Wang, W. Weitao, Effect of Al2O3 and enamel coatings on $90 \square \mathrm{C}$ oxidation and hot corrosion behaviors of gammaTiAl, Mater. Sci. Eng. A 276 (2000) 70-75. https://doi.org/10.1016/S0921-5093(99)00513-4.

9. S. P. Rodtsevich, S. Y. Eliseev, V.V. Tavgen', Low-melting chemically resistant enamel for steel kitchenware, Glass Ceram. 60 (2003) 23-25. https://doi.org/10.1023/A:1023886032228.

10. A. M. Compagnoni, Reduction or elimination of vanadium in enamel for aluminium, Proceedings of the XXI International Enamellers Congress, IEC, Shangai, 18-22 May 2008.

11. M. Zhou, K. Li, D. Shu, B. D. Sun, J. Wang, Corrosion resistance properties of enamels with high B2O3-P2O5 content to molten aluminum, Mater. Sci. Eng. A 346 (2003) 116-121. https://doi.org/10.1016/S0921-5093(02)00527-0.

12. M. Saad, M. Poulain, M. El Farissi, Fluoride enamels for aluminium, J. Non-Cryst. Solids 161 (1993) 141-147. https://doi.org/10.1016/0022-3093(93)90686-R.

13. S. Rossi, L. Bergamo, V. Fontanari, Fire resistance and mechanical properties of enamelled aluminium foam, Mater. Des. 132 (2017) 129-137. https://doi.org/10.1016/j.matdes.2017.06.064.

14. S. Rossi, L. Bergamo, M. Calovi, V. Fontanari, Effect of enamel coatings on the mechanical properties of aluminium foams, Mech. Adv. Mater. Struct. 26 (2019) 1130-1139. https://doi.org/10.1080/15376494.2018.1430278.

15. J. Weizhong, Y. Wang, L. Gu, Influence of TiO2 film on photo-catalytic property of enamels, J. Non-Cryst. Solids 353 (2007) 4191 4194. https://doi.org/10.1016/j.jnoncrysol.2007.06.072

16. E. Scrinzi, S. Rossi, The aesthetic and functional properties of enamel coatings on steel, Mater. Des. 31 (2010) $4138-4146$. https://doi.org/10.1016/j.matdes.2010.04.030.

17. G. Ling, J. He, The influence of nano-Al2O3 additive on the adhesion between enamel and steel substrate, Mater. Sci. Eng. A 379 (2004) 432-436. https://doi.org/10.1016/j.msea.2004.03.019.

18. F.-S. Shieu, K.-C. Lin, J.-C. Wong, Microstructure and adherence of porcelain enamel to low carbon steel, Ceram. Int. 25 (1999) 2734. https://doi.org/10.1016/S0272-8842(97)00080-1.

19. L. Samiee, H. Sarpoolaky, A. Mirhabibi, Microstructure and adherence of cobalt containing and cobalt free enamels to low carbon steel, Mater. Sci. Eng. A 458 (2007) 88-95. https://doi.org/10.1016/j.msea.2006.12.108.

20. J. Weizhong, W. Ying, D. Qi, Influence of the superfine crystal of Li2Ni8O10 as mill addition on the enamel adherence, Mater. Lett. 58 (2004) 1611-1615. https://doi.org/10.1016/j.matlet.2003.10.035. 
21. M. B. Lupescu, M. Zaharescu, A. Andrei, Electron spectroscopy studies of the steel/ enamel interface, Mater. Sci. Eng. A 232 (1997) 73-79. https://doi.org/10.1016/S0921-5093(97)00095-6.

22. A. Zucchelli, M. Dignatici, M. Montorsi, R. Carlotti, C. Siligardi, Characterization of vitreous enamel-steel interface by using hot stare ESEM and nano-indentation techniques, J. Eur. Ceram. Soc. 32 (2012) 2243-2251. https://doi.org/10.1016/j.jeurceramsoc.2012.03.008

23. W. E. Matthews, Keramische Glasuren, second ed., Augustus-Verlag, Augsburg, 1997.

24. I. M. Hutchings, P. Shipway, Tribology: Friction and Wear of Engineering Materials, second ed., Butterworth-Heinemann, Oxford, 2017.

25. R. G. Bayer, Mechanical wear prediction and prevention, Marcel Dekker, New York, 1994

26. S. Rossi, M. Fedel, F. Deflorian, N. Parziani, Abrasion and chemical resistance of composite enamel coatings with hard particles, Surf. Interface Anal. 48 (2015) 827-837. https://doi.org/10.1002/sia.5849.

27. S. Rossi, E. Scrinzi, Evaluation of the abrasion resistance of enamel coatings, Chem. Eng. Process. 68 (2013) 74- 80. https://doi.org/10.1016/j.cep.2012.10.009.

28. E. Scrinzi, S. Rossi, F. Deflorian, Effect of slurry mechanical damage on the properties of an organic coating system, Surf. Coat. Tech. 203 (2009) 2974-2981. https://doi.org/10.1016/j.surfcoat.2009.03.025.

29. S. Suzuki, E. Ando, Abrasion of thin films deposited onto glass by the Taber test, Thin Solid Films 340 (1999) 194-200. https://doi.org/10.1016/S0040-6090(98)01360-1.

30. S. Rossi, M. Calovi, D. Velez, J. Munoz, Influence of addition of hard particles on the mechanical and chemical behavior of vitreous enamel, Surf. Coat. Tech. 357 (2019) 69-77. https://doi.org/10.1016/j.surfcoat.2018.09.062.

31. S. Rossi, C. Zanella, R. Sommerhuber, Influence of mill additives on vitreous enamel properties, Mat. Des. 55 (2014) $880-887$. https://doi.org/10.1016/j.matdes.2013.10.059.

32. S. Rossi, N. Parlini, C. Zanella, Abrasion resistance of vitreous enamel coatings in function of frit composition and particle presence, Wear 332-333 (2015) 702-709. https://doi.org/10.1016/j.wear.2015.01.058.

33. S. Rossi, N. Gasparre, V. Fontanari, A. M. Compagnoni, Modification of the mechanical properties of vitreous enamelled aluminium substrate adding graphene flakes, Key Engineering Materials 813 (2019) 49-54. http://dx.doi.org/10.4028/www.scientific.net/KEM.813.49.

34. K. Shaw, Technology of Enamels, McLaren and Sons LTD, London, 1965.

35. Y. W. Bao, Y. C. Zhou, X. X. Bu, Y. Qiu, Evaluating elastic modulus and strength of hard coatings by relative method, Mat. Sci. Eng. Struct. A 458 (2007) 268-274. Https://doi.org/:10.1016/j.msea.2006.12.131.

36. J. M. Miguel, J. M. Guilemany, B. G. Mellor, Y. M. Xu, Acoustic emission study on WC-Co thermal sprayed coatings, Mater. Sci. Eng. A 352 (2003) 55-63. https://doi.org/10.1016/S0921-5093(02)00546-4.

37. U. Wiklund, M. Bromark, M. Larsson, P. Hedenqvist, S. Hogmark, Cracking resistance of thin hard coatings estimated by four-point bending, Surf. Coat. Tech. 91 (1997) 57-63. https://doi.org/10.1016/S0257-8972(96)03123-4.

38. D. Dalmas, S. Benmedhakène, H. Kébir, C. Richard, A. Laksimi, J. M. Roleandt, Investigation of failure mechanisms in WC-Co coated materials, Surf. Coat. Tech. 173 (2003) 130-143. https://doi.org/10.1016/S0257-8972(03)00464-X.

39. X. Q. Ma, S. Cho, M. Takemoto, Acoustic emission source analysis of plasma sprayed thermal barrier coatings during four-point bend tests, Surf. Coat. Tech. 139 (2001) 55-62. https://doi.org/10.1016/S0257-8972(01)00995-1.

40. V. Dal Re, L. Rossetti, A. Zucchelli, An experimental procedure for the estimation of the porcelain enamelcomposite mechanical performances, Danubia Adria Symposium on Experimental Methods in Solid Mechanics, September 26-29, 2006, Podbanské, Slovak Republic

41. S. Zhang, D. Sun, Y. Fu, H. Du, Toughness measurements of thin films: a critical review, Surf. Coat. Tech. 198 (2005) 74-84. https://doi.org/10.1016/j.surfcoat.2004.10.021.

42. G. Gille, Investigations on mechanical behaviour of brittle wear-resistant coatings II: Theory, Thin Solid Films 111 (1984) $201-218$. https://doi.org/10.1016/0040-6090(84)90142-1.

43. S. Zhang, D. Sun, Y. Fu, H. Du, Effect of sputtering target power on microstructure and mechanical properties of nanocomposite ncTiN/a-SiNx thin films, Thin Solid Films 447-448 (2004) 462-467.

44. S. Zhang, D. Sun, Y. Fu, H. Du, Toughness measurements of ceramic thin films by two-step uniaxial tensile method, Thin Solid films 469-470 (2004) 233-238. https://doi.org/10.1016/j.tsf.2004.08.094.

\section{Keywords}

porcelain enamel; mechanical properties; abrasion; fracture toughness

(C) 2020 by the author(s). Distribute under a Creative Commans CC BY license 